\title{
Analysing the learning by developing action model in HE computing.
}

\author{
LINTILÄ, T. and ZARB, M.
}

2020

(C) 2020 IEEE. Personal use of this material is permitted. Permission from IEEE must be obtained for all other uses, in any current or future media, including reprinting/republishing this material for advertising or promotional purposes, creating new collective works, for resale or redistribution to servers or lists, or reuse of any copyrighted component of this work in other works. 


\section{Analysing the Learning by Developing Action Model in HE Computing}

\author{
Taina Lintilä \\ School of Computing Science and Digital Media \\ Robert Gordon University \\ Aberdeen, United Kingdom \\ taina.lintilae@rgu.ac.uk
}

\author{
Mark Zarb \\ School of Computing Science and Digital Media \\ Robert Gordon University \\ Aberdeen, United Kingdom \\ m.zarb@rgu.ac.uk
}

\begin{abstract}
This Research to Practice Working Process presents the first phase of the study, in which background information was sought from the literature and by interviews pedagogical experts from Laurea University of Applied Sciences (Laurea). The background study sought to gain an understanding of what factors influenced the introduction of the Learning by Developing (LbD) approach at Laurea. Background information is important for the study because the LbD Action Model will also be piloted at another institution during this study. The LbD model is piloted at Robert Gordon University (RGU), in the UK, where background research is also carried out, as cultural factors and pedagogical models tend to vary widely around the world and therefore it is essential to understand them.

The main aim of this research is to find out whether the Learning by Developing (LbD) Action Model is a suitable teaching approach to be used within a computing science curriculum. The study will be carried out in two higher education institutions: Laurea in Finland and RGU in the UK. The subjects of the study are computing students, lecturers and other staff members at both of these higher education institutions, as well as clients participating in the chosen study modules.
\end{abstract}

Keywords-computer science, computing, teaching methods, learning by developing

\section{INTRODUCTION}

Teaching and learning has changed over the years in higher education. Today, the focus is on learning rather than teaching, because the traditional teaching methods are no longer well suited to modern society [1]. The Learning by Developing Action Model (LbD) has been used as the main teaching method in Laurea since 2004, forming part of its underlying strategic model. Rajj [2] identified a pragmatic concept of learning as the basis for the LbD approach. Furthermore, Raij and Taatila have demonstrated LbD's philosophical connections to John Dewey's pragmatic philosophy in their research. According to the pragmatic concept of knowledge, the purpose of education is not only to increase general knowledge, but to answer what and why should be learned and what learning is used for. The world is extremely complex and contains many variables that interact with each other. As we strive for better solutions in new situations, a pragmatic approach to learning also emphasizes the importance and value of continuous learning [3]. Nowadays, pragmatism-based learning approaches are of an even greater value than in the LbD creation phase. [4].
This study collects and analyses information that can be used to develop the LbD Action Model that Laurea has been using since 2004 to better meet today's needs. In the first phase, research data has been collected through interviews with Laurea pedagogy experts in addition to the literature review, and these findings are presented in this article.

The next phase of the research focused on Laurea computing students. Computer science students were chosen for the research as LbD has never been evaluated with them, despite the often practical-based nature of their learning activities. The purpose of this study is to find out how well the LbD approach fits for computer science studies and what kind of learning experiences it provides for students, as well as how student skills develop during the study module. Information was collected from Laurea computer science students through a questionnaire and learning diaries. The research data has also been collected from Laurea lecturers and clients who participated in the study module. The research data from lecturers and clients has been collected through interviews.

A secondary purpose of the study is also to pilot an LbD Action Model at RGU in the UK to see if it can be a valid pedagogical model to use. After the Laurea research phase, a revised LbD Guide will be produced, which will then be piloted in two different study modules at RGU. The purpose of this pilot research is to determine whether the LbD Action Model would also be suitable for computing studies at RGU. Before the piloting the $\mathrm{LbD}$ approach at $\mathrm{RGU}$, the research literature on the background factors of RGU will be done and research data from RGU pedagogical experts will be collected by interviewing them.

\section{BACKGROUND IN FINLAND AND LAUREA}

\section{A. Dual model and the University on Applied Sciences} (UAS) Act

In Finland, the so-called dual model is used in higher education, where both the Universities of Applied Sciences (UAS) and universities have their own role. The role of UAS is more focused on professional and practical skills and applied research, mainly for the needs of business, while universities carry out more basic and advanced scientific researcer [5]. One of the starting points for this has been the Bologna process since 1999 where the Ministers of Education of 29 countries agreed on a common vision of a European Higher Education Area (EHEA). One of the important issues in the Bologna Process and the EHEA has been identified that the student-centred learning is important. Student-centred 
learning, as a whole, influences the learning / teaching process and can only work if both students and teachers are ready to engage in constructive dialogue and a collaborative learning process that develops useful knowledge and creates favourable learning environments. [6.]

In 2003, the University of Applied Sciences Act was passed in Finland, which defines the tasks of the University of Applied Sciences. The latest version of Chapter 1, Section 4 of the UAS Act 2014 states that the task of UAS is to provide higher education based on the requirements of working life and its development, as well as research, artistic and cultural background and to support students' professional development. The second section of the fourth section of Chapter 1 of this Act was amended in 2018. The amended Act states: The University of Applied Sciences is also responsible for applied research, development, innovation and artistic activities serving UAS education, promoting employment and regional development and modernizing the enterprise structure. In carrying out its tasks, the university of applied sciences must provide opportunities for continuous learning [7].

\section{B. Learning by Developing ( $L b D)$}

Institution I has implemented the Learning by Developing (LbD) Action Model [3] to provide students with the advance and future-oriented pedagogical support. The LbD is based on pragmatism and it focuses on a development project that is genuinely connected to real-life workspaces [8]. The name, Learning by Developing, was already used in the early stages of the LbD development process, with a strong background in applying exploratory learning [9] to teaching. Later, a closer look at the philosophical underpinnings of the concept of learning revealed that there was a pragmatic concept of learning behind it [10].

The features of LbD are authenticity, partnership, trust, creativity and an exploratory approach in which all partners participate as equals, sharing experiences and finding meanings to produce new knowledge in their different roles and responsibilities [3]. LbD is not only a learning process, but also a process of reasoning and research. It helps students to continuously exchange knowledge and skills according to the requirements of the project. At the same time, the LbD supports students to reinvent their skills, knowledge, and even identity over and over again. The goal of the $\mathrm{LbD}$ is to prepare students for working life and for changing it in the future.

\section{RESEARCH STRATEGY, METHODS \& GOALS}

The research strategy chosen for this study is action research, which is discipline-based research conducted by a teacher in order to seek information and change his or her practice in the future [11]. This is a process whereby participants systematically and carefully review their own teaching practices using research methods [12]. Educational action research can be attended by the entire school's faculty, a group of teachers sharing a common problem, or just a single teacher [13]. Action research fits into the research strategy of this study, since the purpose of the study is to develop LbDbased teaching practices in Laurea, and possible to implement it in the RGU as well. LbD Action Model has been used in Laurea since 2004. This study has initially gathered background information from both the literature and Laurea's $\mathrm{LbD}$ experts through interviews to find out the current state. Conducting this background study at Laurea is important because it provides information on what was the starting point and background factors for the introduction of $\mathrm{LbD}$ at Laurea.
In addition, the expert interviews provide genuine information on how the use of LbD has gone at Laurea and what development needs the use of LbD has raised. Interviews with experts also provide information on the current situation regarding $\mathrm{LbD}$ in Laurea, which is vital information for piloting $\mathrm{LbD}$ at RGU.

In Laurea, more LbD-related research has been done in the past among students in the social and tourism and restaurant sectors, but not specifically in computer science students. One of the aims of this study is to find out if the LbD approach is also a suitable learning method for computer science students and to find out what their learning experiences are through LbD, as well as to find out how their skills develop in an LbD based study module. In the first research cycle related to the study module of the action research, research data were collected from Laurea's computing students through a questionnaire and learning diaries. Research data through interviews were collected from lecturers and participating clients. Participating clients are genuine representatives of working life who have been selected for the study module. During the study module, the student groups make a real customer project implementation with them. The interviews were used to find out how well the LbD model, in the lecturer's view, fits into computing students' study modules and how lecturers should be trained to use LbD in order for it to work properly. The participating clients are the real-life customers The purpose of the customer interviews was to find out how useful they found participation in the LbD-based study module on the role of the client and how well this model suited the needs of the clients and how well it was implemented.

After this cycle of data collection and analysis, a revised LbD guide will be created. The LbD guide can be used to guide lecturers as they apply the LbD approach to teaching at Laurea. Laurea has identified the need for a new LbD guide and it is being developed jointly at Laurea. The following cycles of this study are intended to pilot the use of LbD in the RGU and therefore the LbD guide must be sufficiently comprehensive and clear to be used in the context of the pilot study.

\section{THE RESULTS OF BACKGROUND RESEARCH}

Background research is very important in this study. In addition to the literature, research data were collected by interviewing Laurea's LbD experts. Five experts employed by Laurea and one retired expert from Laurea were selected for the interview. The interviews were conducted as thematic interviews, some of which was conducted as personal interviews and some as online interviews using Zoom. All interviews were recorded and transcribed. All responses were then collected in the same file so that they could be qualitatively analysed.

The experts were asked what are the general background factors for the introduction of the LbD approach and what they consider to be its absolute preconditions. The main background factors taken from the experts' responses were: co-operation and development of working life, the suitability of the organisation's learning concept and culture for adopting a new approach, and the structure of the organisation's pedagogical philosophical knowledge base.

According to the experts, the absolute prerequisites were: working life cooperation and understanding of LbD's pedagogical approach, adequate mapping of organizational needs and requirements, adequate training and time for 
internalization, continuous work and development, strong interest in working with companies that understand the importance of cooperation and changes in the roles of both students and teachers.

According to experts, the main background to the introduction of the $\mathrm{LbD}$ at Laurea was an amendment to the 2003 law requiring the UAS to carry out applied research and assigning the UAS three tasks: regional development, research and teaching. According to one expert, it was also influenced by the recognition of competence-based learning and the development and production of expertise.

Experts were also asked whether they considered the LbD approach to be suitable for all teaching, for all fields of education, for all teachers, for all situations and also for students who are just starting their studies. The answers to the experts to this question differed slightly. Some replied that it didn't fit everything and some thought it would fit. However, everyone believes that $\mathrm{LbD}$ is suitable for most studies and is also suitable for all fields, as long as a suitable target can be found, although in some areas it may be more challenging.

One expert thought that using LbD for new students might not be a good idea, but another thought it would be good if first-year students already had a multidisciplinary experience through LbD. According to one expert, LbD is good for all learning, but then one has to think about how the learning environment is constructed to have all the necessary components of competence: knowledge, understanding, skills and situation management, and values must be underpinned when it comes to types of knowledge. When all the components of competence and knowledge are present in the learning environment, it enables the acquisition of knowledge.

Experts were also asked what impact the LbD approach has had on Laurea's teaching. According to the panel of experts, it has sparked a lot of discussion about polytechnic pedagogy, and through it Laurea gained a reputation as a different actor and demonstrated the ability to apply theoretical knowledge to practical working life. This caused some envy in other UAS. The introduction of the LbD approach changed the role of the teacher and brought a whole new dimension to learning, and the competence-based approach was adopted as a Laurea's way. The use of LbD brought recognition to Laurea with the achievement of several development awards.

Experts were also asked about their personal experiences and, in general, the experiences of teachers and students in using the LbD approach. Experts who used LbD themselves said the experience was positive because they had been interested in it and willing to try something new. The students' experiences had also been largely positive and they had felt that they were now really learning and internalizing things, and they were excited about it. At the same time, they also gained working life contacts and internships, which was important to them. Of course, there were also students who were not very spontaneous and did not like the new way of learning.

One expert had used LbD with international students, and the challenge at the time had been that exchange students were not accustomed to the LbD approach. International students were accustomed to the traditional hierarchical model in their home country and the distance between teacher and student. In general, the experiences of different teachers have varied quite a lot. Many teachers only experienced LbD as a working life project and the pedagogical process of LbD was not very clear to them. Some teachers were eager to implement the LbD approach right from the start, but there were sceptics as well, and some may never even have tried it. Experiences with LbD and its use were highly dependent on the teacher's own motivation and activity. It was very natural for some to use it and they had good skills and great interest in it, while teachers accustomed to more traditional teaching methods were not very enthusiastic about it. In the beginning, there was a lot of opposition to the use of LbD also because it was introduced at Laurea at the beginning so that everyone is forced to use it.

Expert interviews also sought to find out how they thought teachers could apply this new way of teaching. All experts had a fairly unified view on this topic. They believe that a clear strategy, a strong will, a positive atmosphere and a willingness to try new things are needed. In addition, teachers should not be left alone, they should have training available and support should always be available. Most often, resistance to change stems from a person's insecurity and fear of new things. Teachers therefore need to be guided to find a purpose for why $\mathrm{LbD}$ is a good way and to make them understand their role in it.

The background questions also asked how teachers are introduced to the LbD approach, how its use and expertise is maintained, and how LbD is developed at Laurea. Experts were in agreement that familiarity with the $\mathrm{LbD}$ approach is currently rather poorly managed, but recognised that it is teacher-dependent. In units and training areas where it has been used systematically all the time, it is also better managed. However, it has recently received too little attention in the induction of new teachers. One expert said that during the introduction phase of $\mathrm{LbD}$, there was an induction program at Laurea and mentors were appointed for all new teachers. All experts recognized that there are currently many shortcomings in introducing $\mathrm{LbD}$, but mentioned that 2020 has been designated by Laurea as the "LbD Year", with the aim of highlighting $\mathrm{LbD}$ more and encouraging lecturers to try it. $\mathrm{LbD}$ has now been raised as one important development project and has been included in Laurea's strategy.

Measures for the progress of the LbD development project have already been planned and partially implemented, and during 2020 the goal is to create clear action plans and continuously develop LbD with agility. Several events have already been agreed for 2020 and the new LbD competence label will be introduced at Laurea and everyone is encouraged to complete it. In addition, instructions are given on how LbD can also be used in online implementations.

All experts were also asked if they would recommend the LbD approach to other universities around the world. Most experts would definitely recommend it, though some with a small reservation. Everyone agreed that the LbD approach is a good pedagogical model and fits into today's society, but it needs to be adapted to organizational structures and culture and it also requires co-teaching. The LbD Action Model is a good way if the goal is competence, and not just that the student is able to produce information about what someone has taught him or her.

\section{PRELIMINARY RESULTS FROM COMPUTING STUDENTS RESEARCH}

At Laurea, the collection of research data was carried out in connection with the Service Design study module implemented in autumn 2019. Research data have been collected from students and lecturers who participated in that study module, as well as from company representatives. The total number of students in that study module was 36 students, of which seven were exchange students. The language of the course was English. At the beginning of the study module, 
students were informed about this study and asked to keep a learning diary during the study module. In addition, they were told that a questionnaire would be sent to them at the end of the study module, which would also be used to collect research data. At the beginning of the study module, it was also explained what the LbD approach is about so that students, lecturers and clients understand their own role and are able to act accordingly.

The research strategy of this research is action research and the researcher participates in teaching with another lecturer during the course. In addition to this study module, research data were collected by interviewing two other lecturers who simultaneously implemented a similar study module for business students. Research data were also collected from all clients who participated in the study module by interviewing them. The students were divided into six groups and each group had a different task. The two groups had the same client, so a total of five clients participated in the interview.

The classification and analysis of research results are still ongoing, but some preliminary results can already be reviewed. 29 students from 36, responded to the survey. Nine of the respondents were female students. More than half of the students were between the ages of 18 and 25 , four between the ages of 26 and 30, five between the ages of 31 and 36, and one between the ages of 36 and 40, and one aged 41 or more (Figure 1). Most of the students (19) were third-year students. Nine students were second-year students and one student has studied for more than three years. Students were asked to rate their own skills that are general and common working life competencies in the studies leading to Laurea's degrees: selfmanagement and entrepreneurial attitude, critical thinking and problem-solving skills, anticipation and innovation skills, communication and interaction skills, global skills. At the time of publication, these research findings have not yet been analysed.

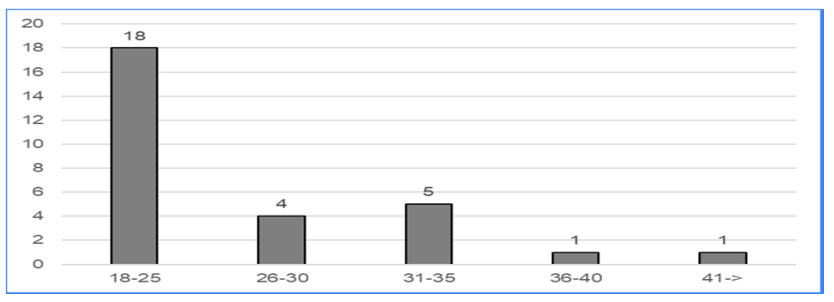

Figure 1: Age distribution of the respondents

In addition to these quantitative questions related to competence development, the questionnaire included questions that students were asked to answer by writing freeform text. One answer given by students related to the understanding of $\mathrm{LbD}$ and a few example answers from freeform text fields are cited as examples in this article. The research results related to the development of students' competence will be examined in the next phase of the research.

The first question related to LbD (Figure 2) was: "How well have you understood what the LbD Action Model means in practice ?" Students were asked to answer this numerically on a scale of 1 (poor) to 5 (very good). Average level of understanding was 3,86 and standard deviation was 0,86 . Based on these results, it can be concluded that most of the students felt that they had a good or moderate understanding of what the LbD means in practice.

Students were also asked to describe freely in their own words, what the LbD approach means in practice. A more

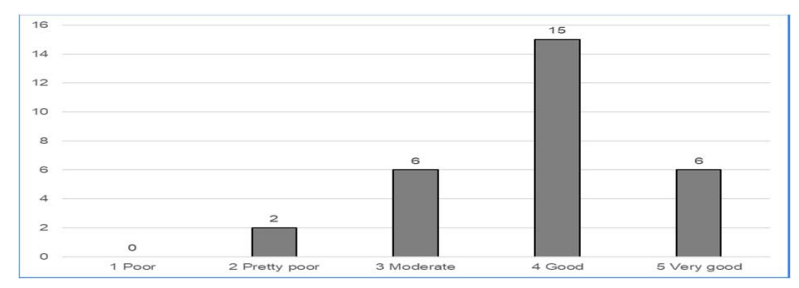

Figure 1: Understanding of what the LbD in practice means

detailed analysis of the results has not yet been done, but a comparison with the students 'free-form responses and their own numerical estimates, the results are not entirely consistent. For example, two students whose own numerical assessment of LbD understanding was 'pretty poor' were able to describe quite well what $\mathrm{LbD}$ means in practice. On the other hand, a few students whose free-form descriptions show that they did not understand very well what the LbD approach means in practice had themselves estimated that they understood the meaning of LbD very well. Here are a couple examples of those student answers: "you learn things by doing things", "you recognize and find yourself the way" and "you do things in a congested and chaotic way with results (usually worthless)". These responses are worth exploring further, but they may indicate that students had not correctly understood the significance of LbD or that they were not fully engaged in this study. The next phase of the research will analyse the research results of students, lecturers and clients in more detail.

\section{CONCLUSIONS}

The research strategy of this study is action research and has many different phases, which is typical of action research. The main purpose of action research is to develop the practices of the target organization under study, which in this study are related to the development of teaching practices. Two different educational organizations are involved in the study, and this article mainly describes the background factors of the study in one of these organizations, Laurea, where this study was started. The background study described in this article has provided a good starting point for the next stages of the study, from which research data for the next cycle has already been collected. The background factors for the development of LbD and its introduction in Laurea have been clarified. The current state of LbD in Laurea and the needs for its development have also been identified and it is a good starting point for the next stages of research.

The summary of the background research is that $\mathrm{LbD}$ is a pedagogical model that fits well into today's society, but its use requires its adaptation to organization, culture and, in addition, it requires co-teaching as well as strong collaboration in working life. The LbD approach is a good way if the goal is competency-based learning, and not just information produced by students about what someone has taught them.

After a more detailed analysis of the research data collected at Laurea, a revised LbD guide will be produced. The LbD guide is used in the development of Laurea's teaching and teacher orientation, as well as in the pilot study of the LbD Action Model at RGU. The purpose of the pilot study of the LbD Action Model at RGU is to find out whether LbD can be successfully applied in RGU and whether it is also suitable for RGU's computing students. The aim of this study is also to identify the further development needs of $\mathrm{LbD}$ and to ensure that it also takes into account the international perspective and future needs. 


\section{REFERENCES}

[1] Siegel, M.A. \& Kirkley, S. 1997. Moving Toward to Digital Learning Environment: The Future of Web-Based Instruction. In Khan, B.H (ed.) Web-Based Instruction. Englewood Cliffs. New Jersey07532: Educational Technology Puclications.

[2] Raij, K. 2012. Summarising the basis of LbD for further development - review. Laurealaisella Väylällä.

[3] Raij, K \& Taavila, V. 2012. Philosophical Review of Pragmatism as a Basis for Learning by Developing Pedagogy. Educational Philosophy and Theory, Vol. 44, No. 8

[4] Rauhala, P. 2020. LbD Laurean pedagogiikan kulmakivenä. Laurea Journal. Accessed on 7 February 2020 Retrieved from https://journal.laurea.f8/lbd-laurean-pedagogiikan-kulmakivena

[5] Act 351/2003. Ammattikorkeakoululaki [Act on University of Applied Sciences. Accessed 4 April 2020. Retrieved from https://www.finlex.fi/fi/laki/alkup/2003/20030351

[6] EHEA ministerial conference Yerevan. 2015. The Bologna Process Revisited: The Future of the European Higher Education Area

[7] Act 1368/2018. Laki ammattikorkeakoululain muuttamisesta [Act Amending the University of Applied Sciences. Accessed 5 April 2020. Retrieved from https://www.finlex.fi/fi/laki/alkup/2018/20181368

[8] Raij, K. (2007) Learning by Developing. Laurea Publications. A58. Laurea University of Applies Sciences.

[9] Hakkarainen, K. \& Lonka, K. \& Lipponen, L. 2004. Tutkiva oppiminen. Porvoo: WSOY.

[10] Taatila, V. \& Raij, K. 2011. Philosophical Review of Pragmatism as a Basis for Learning by Developing Pedagogy. Educational Philosophy and Theory. Volume 44, Issue 4, 831-844.

[11] Ferrance, E. 2000. Action Research. Themes in Education. Northeast and Islands Regional Educational Laboratory. Brown University.

[12] Taber, K. S. 2013. Action Research and the Academy: seeking to legitimise a 'different' form of research Teacher Development, 17(2), 288-300.

[13] Sagor, R. 2000. Guiding School Improvement with Action Research. Association for Supervision and Curriculum Development. Alexandria. USA. 